
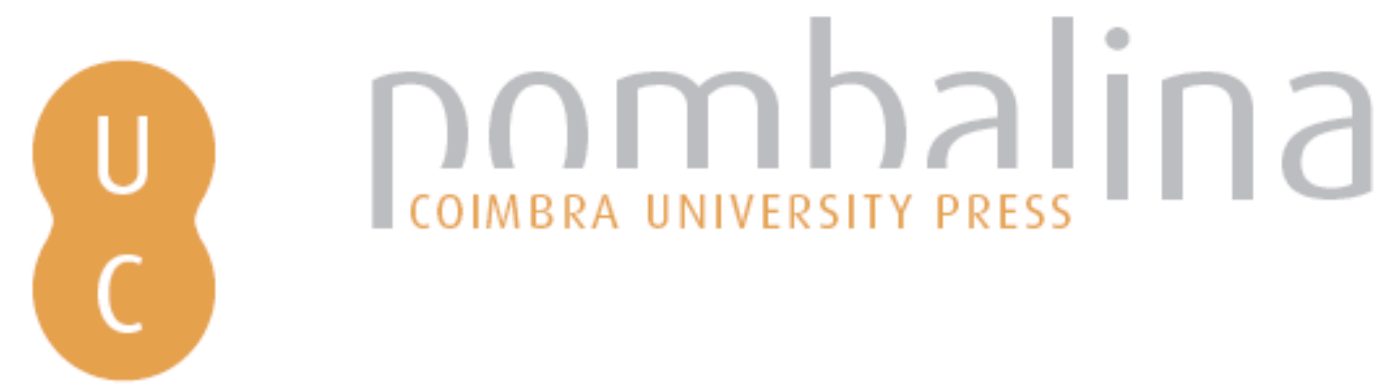

\title{
"Cidadania e profissionalidade": uma nova disciplina leccionada por professores de geografia: reflexão sobre os desafios teóricos e metodológicos que encerra para os professores-geógrafos
}

\author{
Autor(es): Martinha, Cristiana
}

Publicado por: Imprensa da Universidade de Coimbra

URL persistente:

URI:http://hdl.handle.net/10316.2/30755

DOI:

DOI:http://dx.doi.org/10.14195/978-989-26-0244-8_4

Accessed : $\quad$ 26-Apr-2023 14:41:07

A navegação consulta e descarregamento dos títulos inseridos nas Bibliotecas Digitais UC Digitalis, UC Pombalina e UC Impactum, pressupõem a aceitação plena e sem reservas dos Termos e Condições de Uso destas Bibliotecas Digitais, disponíveis em https://digitalis.uc.pt/pt-pt/termos.

Conforme exposto nos referidos Termos e Condições de Uso, o descarregamento de títulos de acesso restrito requer uma licença válida de autorização devendo o utilizador aceder ao(s) documento(s) a partir de um endereço de IP da instituição detentora da supramencionada licença.

Ao utilizador é apenas permitido o descarregamento para uso pessoal, pelo que o emprego do(s) título(s) descarregado(s) para outro fim, designadamente comercial, carece de autorização do respetivo autor ou editor da obra.

Na medida em que todas as obras da UC Digitalis se encontram protegidas pelo Código do Direito de Autor e Direitos Conexos e demais legislação aplicável, toda a cópia, parcial ou total, deste documento, nos casos em que é legalmente admitida, deverá conter ou fazer-se acompanhar por este aviso.

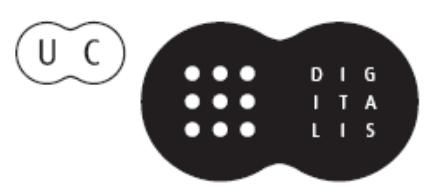




\section{TRUNFOS DE UMA}

\section{EOGRAFIA ACIVA}

\section{DESENVOLVIMENTO LOCAL,}

AMBIENTE,

ORDENAMENTO

E TECNOLOGIA

Norberto Santos

Lúcio Cunha

COORDENAÇÃO 
Cristiana Martinha

Faculdade de Letras da Universidade do Porto/CEGOT

\title{
“CIDADANIA E PROFISSIONALIDADE” - UMA NOVA DISCIPLINA LECCIONADA POR PROFESSORES DE GEOGRAFIA - REFLEXÃO SOBRE OS DESAFIOS TEÓRICOS E METODOLÓGICOS QUE ENCERRA PARA OS PROFESSORES-GEÓGRAFOS
}

\section{INTRODUÇÃO}

\begin{abstract}
A educação de adultos, considerada um campo específico das ciências da educação, estabeleceu um vínculo próprio com a noção de competência. Edmée Ollagnier (2004:190)
\end{abstract}

É nosso objectivo debater, do ponto de vista teórico e metodológico, o processo de leccionação da área de competência-chave "Cidadania e Profissionalidade" (inserida no Referencial de Competências-Chave para a Educação e Formação de Adultos - Nivel Secundário) pelos professores de Geografia, tratando-se "de uma modalidade com características inovadoras no âmbito da educação e formação de adultos, para a qual muitos professores de Geografia foram mobilizados", segundo Lavrador, Reis e Carneiro (2009:1).

De acordo com o Referencial, o processo de Educação e Formação de Adultos de nível secundário organiza-se de acordo com três áreas de competência-chave: "Cidadania e Profissionalidade" (CP); "Sociedade, Tecnologia e Ciência" (STC) e "Cultura, Língua e Comunicação” (CLC).

Este projecto visa “(...) a criação de condiçôes que, no tempo, alarguem à população adulta o direito de ver formalmente reconhecidos os saberes e competências adquiridos ao longo da vida e, se necessário, completá-los para efeitos de obtenção de uma certificação de nivel secundário (...)" (in Referencial de Competências-Chave para a Educação e Formação de Adultos - Nivel Secundário, 2006:7), corporizando, em parte, o projecto "Novas Oportunidades".

No sentido de reflectir didacticamente sobre este assunto, iremos ao longo dos próximos pontos de reflexão, equacionar os conceitos de "competência" e de "competência-chave" que norteiam a organização desta modalidade de formação de nível secundário; faremos uma apresentação dos núcleos geradores/temas da área de "Cidadania e Profissionalidade” por tratar-se daquela área que os docentes de Geografia essencialmente leccionam

\footnotetext{
${ }^{1}$ Os autores da área de "Cidadania e Profissionalidade" são: José Manuel Pureza (coordenação); Isabel Ferreira Martins e Olga Marques Filipe.
} 
nesta modalidade de ensino; discutiremos as principais metodologias de ensino/avaliação associadas a este tipo de ensino, e serão abordadas as principais "linhas de adaptação" que é urgente aplicar à formação inicial de professores de Geografia (e História) de modo a capacitar estes novos professores para leccionarem, com o maior rigor científico e metodológico, esta área de competência-chave. Valorizamos, em especial, a necessidade de renovação da formação inicial, na medida em que muitos dos professores que são recém-profissionalizados acabam por ter uma experiência de leccionação nesta modalidade de ensino. Quanto aos docentes que já então envolvidos nesta modalidade de ensino, frequentemente realizam formação específica proporcionada pela ANQ (Agência Nacional para a Qualificação) quando inseridos no âmbito de um CNO, apesar de existir também necessidade de formação contínua, como referem Lavrador, Reis e Carneiro (2009:9), destacando que "se deve investir na formação contínua dos docentes através de aç̧óes de formação especificas para as três Áreas de Competência-Chave".

Com a apresentação deste texto perante a comunidade de geógrafos portugueses pretendemos alcançar três objectivos:

a) promover a discussáo em torno dos conhecimentos/competências dos geógrafos, por parte de um dos seus principais empregadores - o Ministério da Educação;

b) promover a reflexão em torno do lugar do Ensino da Geografia (ou de conteúdos geográficos) em novas modalidades de ensino de modo a defender a importância da sua presença;

c) lançar pistas para a renovação da formação inicial de professores de Geografia de modo a defender a continuação de um dos "pontos fortes" desta formação (a boa adaptação às necessidades do mercado de trabalho) no âmbito das Universidades Portuguesas.

\section{CONCEITOS DE “COMPETÊNCIA” E "COMPETÊNCIA-CHAVE”}

No contexto da Educação de Adultos há, actualmente, dois conceitos absolutamente nucleares no seu trabalho didáctico - o de "competência" e o de "competência-chave".

Neste domínio, urge destacar que o conceito de "competência" tem sido um dos mais discutidos no âmbito educacional nos últimos anos. Vários são os autores que têm escrito sobre este assunto, entre os quais destaca-se o nome de Perrenoud que afirma que "(...) as competências mobilizam conhecimentos, mas não se reduzem a eles. Manifestam-se na capacidade de um sujeito de mobilizar diversos recursos cognitivos para agir com discernimento diante de situaçôes complexas, imprevisiveis, mutáveis e sempre singulares"(PERRENOUD, 2005:69).

Contudo, Perrenoud defende que o conceito de competência não está estabilizado ou teoricamente fundamentado e, por isso, "o trabalho [é] desenvolvido em areias movediças"

\footnotetext{
2 “(...) assume particular importância a definição clara de dois conceitos: o de competência e o de competências-chave. Entende-se neste documento competência como uma "combinatória de capacidades, conhecimentos, aptidôes e atitudes apropriadas a situações especificas, requerendo também 'a disposição para' e 'o saber como' aprender" (Comissão Europeia, 2004). E neste mesmo sentido, mas de modo mais concreto e circunscrito, a definição de competências-chave é a de "um conjunto articulado, transferivel e multifuncional, de conhecimentos, capacidades e atitudes indispensáveis à realização $e$ desenvolvimento individuais, à inclusão social e ao emprego." (Comissão Europeia, 2004). Estas podem ser adquiridas tanto em percursos formais de escolarizaçâo obrigatória, como podem constituir-se como fundamentos para novas aprendizagens e processos de aquisição de competências" - in Referencial de Competências-Chave para a Educação e Formação de Adultos - Nivel Secundário, 2006:14.
} 
(PERRENOUD, 2001:10). Sublinha ainda que é verdade que não existe, hoje em dia, qualquer definição consensual do conceito de competência, havendo quem conteste a sua relevância (PERRENOUD, 2001:10) ${ }^{3}$.

No que concerne à emergência da sua definição, destacamos que tanto Roldão (2004:9) como Barreira \& Moreira (2004:14) defendem que o conceito entrou no discurso educacional internacional na década de 1990.

No que a este conceito diz respeito, sublinhamos a distinção feita por Alves (2006:66) que defende que se pode "distinguir as competências especificas e as competências-chave transferiveis ou aplicáveis para múltiplas situaçôes". Deste modo, quando nos referimos a "competências-chave" é importante referir que estamos perante uma realidade diferente daquela com que lidamos quando nos referimos às "competências específicas" de uma dada disciplina, como por exemplo, da Geografia definidas no Currículo Nacional do Ensino Básico (2001).

Procurando estabelecer a "ponte" entre estes conceitos e o campo da formação de professores, Perrenoud, define do seguinte modo, as exigências que uma abordagem do processo de ensino-aprendizagem "por competências" exige aos professores:

1. "Por mais especialistas que fossem, sentissem-se antes responsáveis pela formação global de cada aluno [...].

2. Aproveitassem a menor ocasiáo para sair do seu campo de especialização e discutir com seus colegas problemas de método, de epistemologia, de relação com a escrita, com o saber, com a pesquisa [...].

3. Percebessem e valorizassem as transversalidades potenciais nos programas e nas actividades didácticas.

4. Não recuassem regularmente diante de projectos ou de situaçóes-problema [...].

5. Trabalhassem com balanços de conhecimentos e competências à escala de várias disciplinas [...]" (PERRENOUD, 1999:67-68).

Estes são alguns dos desafios que Perrenoud identifica na acção docente num trabalho didáctico de desenvolvimento de competências nos alunos. Sem dúvida, estes reptos devem ser "tratados" ou ser "objecto de sensibilização" no âmbito da formação inicial de professores de modo a capacitar os jovens professores da melhor forma possível a leccionarem "neste registo" tanto na "educaçáo regular" como na "educaçáo de adultos".

\section{Área de COMPETÊNCIA-Chave “CidAdANIA E ProfisSIONALIDADE”“}

De acordo com o Referencial, a área de "Cidadania e Profissionalidade" assume uma importância fulcral como elo de ligaçáo/integraçáo das restantes áreas. A Figura 1 mostra este facto.

\footnotetext{
${ }^{3} \mathrm{Um}$ dos autores portugueses que tem discutido este aspecto é José Augusto Pacheco (2003:61-62), que defende que "competência e objectivo dizem respeito a formas de ordenação do conhecimento ou a critérios para a selecção de estratégias que fundamentam a organização do processo ensinolaprendizagem, que têm em comum uma visão do culto da eficiência e uma noção instrumental de currículo".

4 "Cidadania e Profissionalidade (CP) - Nesta Área, pretende-se evidenciar, reconhecer e certificar competências-chave da e na cidadania democrática resultado da aprendizagem reflexiva elou da (re)atribuição de sentido à experiência e ao conhecimento prévio. Elegem-se para tal duas perspectivas fundamentais, mas profundamente interligadas: a cidadania e a profissionalidade" - in Referencial de Competências-Chave para a Educação e Formação de Adultos - Nivel Secundário, 2006:24.
} 
Área Cidadania

e Profissionalidade (transversal)

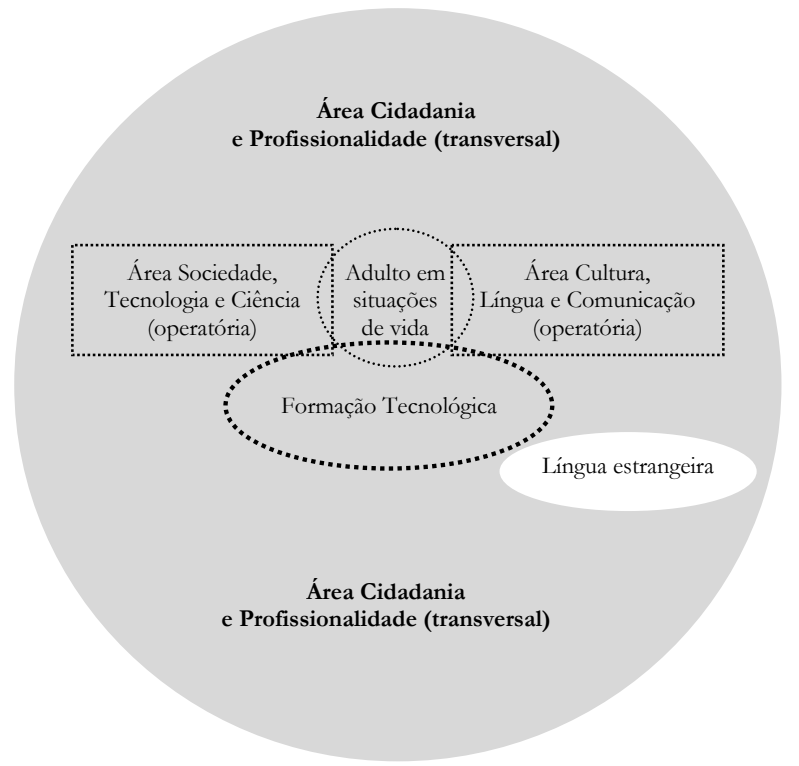

Figura 1 - Desenho do Referencial de Competências-Chave para a educação e formação de adultos (in Guia de Operacionalização de cursos de educação e formação de adultos, 2009:31).

Nesta área, tal como nas demais, as competências a validar organizam-se em núcleos geradores $^{5}$. Os núcleos geradores a serem trabalhados em CP são:

\section{Direitos e Deveres}

Complexidade e Mudança

Reflexividade e Pensamento Crítico

Identidade e Alteridade

Convicção e Firmeza Ética

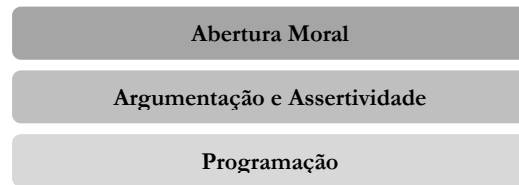

Figura 2 - Núcleos Geradores da área de "Cidadania e Profissionalidade"

(in Referencial de Competências-Chave para a Educação e Formação de Adultos - Nivel Secundário, 2006:36).

Apesar de, como referem Lavrador, Reis e Carneiro (2009:5), "os docentes de Geografia [disporem] de um capital de saberes e experiência capazes de assegurar o desenvolvimento das competências na área de Cidadania e Profissionalidade", o facto de não estarem afectos

${ }^{5}$ É um "tema abrangente, presente na vida de todos os cidadãos a partir dos quais se podem gerar e evidenciar uma série de competências-chave” - in Referencial de Competências-Chave para a Educação e Formação de Adultos Nivel Secundário, 2006:25. 
efectivamente às outras áreas de competência-chave, parece-nos um aspecto demonstrativo da falta de conhecimento das áreas temáticas nas quais os geógrafos apresentam formação/conhecimentos, por parte do ME/ANQ e que merece a mais séria reflexão por parte da comunidade de geógrafos portuguesa.

Neste contexto, parece-nos agora fundamental que a comunidade de geógrafos/professores de Geografia defenda a ideia de que possuímos conhecimentos e competências para leccionarmos temas das outras áreas de competência-chave e que, por isso, "seja alargada aos professores de Geografia a participação como formadores nas outras áreas de competência para além de CP, em particular na área de STC' (LAVRADOR, REIS e CARNEIRO, 2009:9).

\section{As Metodologias de Ensino na EducaÇÃo e FormaÇÃo de Adultos ${ }^{6}$}

Do ponto de vista metodológico, este novo modelo de trabalho didáctico da Educação e Formação de Adultos exige que os professores trabalhem com novas metodologias de ensino e de avaliação. Destacam-se, neste aspecto, a utilização e exploração das "histórias de vida" para se validarem competências e a organização do processo de ensino-aprendizagem em torno da construção de um "portefólio reflexivo das aprendizagens" frequentemente articulado com "actividades agregadoras".

Trata-se, de um modo geral, de metodologias de trabalho didáctico que frequentemente são pouco abordadas no âmbito da formação inicial de professores de Geografia. Se o trabalho de pesquisa, utilização das TIC e a construção de um portefólio ou de organização do processo de ensino-aprendizagem "por competências" são realidades "familiares" a quem recentemente fez formação inicial de professores, outras metodologias como a utilização de "histórias de vida"; os "balanços de competências" e a participação em "júris de validação" são realidades didácticas novas para as quais é necessário formar os jovens professores.

Outra das abordagens metodológicas necessárias é a organização da formação de acordo com "actividades integradoras/agregadoras" defendendo-se que "as metodologias de formaçâo desenvolvem-se numa lógica de "actividades integradoras", que convocam competências e saberes de múltiplas dimensóes, que se interseccionam e entreajudam para resolver problemas em conjunto" (in Guia de Operacionalização de cursos de educação e formação de adultos, 2009:16). Na prática, isto traduz-se na necessidade da equipa pedagógica trabalhar com um tema aglutinador das várias actividades formativas das áreas de competência-chave de modo a dar coerência e significado a essas actividades.

Quanto ao "balanço de competências", este é uma “intervenção indutora da exploração e avaliação das competências" (in Guia de Operacionalização de cursos de educação e formação de adultos, 2009:82). Na prática, este processo implica que os formadores elenquem num documento todas as competências/critérios de evidência que os alunos poderão validar e indiquem aquelas que validaram e de que forma o fizeram.

Decorrente desta breve explicação (marcadamente teórica) sobre a metodologia de trabalho na Educação e Formaçáo de Adultos, importa sublinhar que esta abordagem exige

\footnotetext{
${ }^{6}$ Abordaremos tanto metodologias da modalidade EFA como da modalidade RVCC da Educação de Adultos.
} 
alguma renovação/adequação na formação de professores de Geografia (bem como de outras disciplinas), de modo a tornar esses professores mais capazes para trabalharem nestes contextos formativos, com o máximo de rigor científico e metodológico. Essa formação poderá ser dada nas Universidades directamente pelos seus investigadores da área da metodologia de ensino ou através de seminários recorrendo a convites, para explicaçáo desta modalidade de ensino, a técnicos da $\mathrm{ANQ}^{7}$.

De sublinhar por exemplo que, neste contexto de trabalho didáctico, segundo Lavrador, Reis e Carneiro (2009:7), "a experiência [de leccionaçáo], em par pedagógico, tem exigido muitas horas de trabalho para a planificação conjunta de actividades e requer uma grande flexibilidade [...] O resultado tem sido muito gratificante e a avaliaçáo feita pelos adultos em formação é muito positiva", o que vai ao encontro dos desafios para a formação de professores num contexto de Pedagogia por Competências enunciado por Perrenoud e que já referimos neste texto, justificando a importância da sua abordagem no âmbito da formação de professores.

\section{CONCLUSÃO / PONTOS PARA DisCUSSÃO}

"De uma "banda estreita de formação" a competência transporta-nos para a "banda larga" de preparação para a vida em geral e não apenas para a vida activa (profissional)".

Luís Alberto Alves (2009:43)

Em jeito de conclusão desta nossa reflexão em torno da leccionação da área de competência-chave de "Cidadania e Profissionalidade" pelos professores-geógrafos, destacamos a necessidade de se repensar as áreas que poderão ser leccionadas por geógrafos, abrindo caminho à possibilidade de leccionação efectiva de temas de outras áreas de competência-chave.

Uma possível solução a apoiar nesta questão é a não alocação de um dado professor a uma área de competência-chave em função do seu grupo de recrutamento, mas sim a sua alocação a núcleos geradores específicos das várias áreas, um pouco dentro da filosofia do ensino modular.

Em última instância defendemos, tal como o fez Hargreaves, que "o professor é a chave derradeira para a mudança na educação e para a melhoria da escola" (cit. in ESTRELA, ESTEVES e RODRIGUES, 2002:7). Neste sentido, acreditamos que o sucesso e a melhoria desta nova iniciativa educacional portuguesa dependem fortemente do envolvimento e preparação dos professores. Assim, o presente texto visa configurar-se também como um alerta para a formação inicial de professores de Geografia (agora em conjunto com a História) começar a responder a esta mutaçáo recente do mercado de trabalho do ensino, sob pena da "reforma" falhar, pois tal como referiu João Barroso (2001:81), a "continuidade da gramática da instruçâo frustrou geraçôes de reformadores que sonharam

\footnotetext{
${ }^{7}$ A ANQ (Agência Nacional para a Qualificação) que é o organismo que tutela esta modalidade de ensino e que faz formação aos profissionais que nela trabalham actualmente no terreno.
} 
alterar [...] formas estandardizadas", caso os jovens professores não sejam suficientemente sensibilizados e formados para esta realidade.

Trata-se, no fundo, de perceber que uma abordagem mais abrangente no que à formação de professores de Geografia (e de outras disciplinas) diz respeito, exige uma formação mais "afinada" do ponto de vista teórico e das metodologias de ensino, pois tal como refere Philippe Perrenoud (1999:67), "uma compartimentação disciplinar menos rígida [como é o caso da área de "Cidadania e Profissionalidade"] exige, paradoxalmente, uma formação disciplinar e epistemológica mais afinada dos professores”, capaz de responder ao desafio da "banda larga" de formação que a abordagem do processo de ensino-aprendizagem "por competências" lança.

\section{FONTES CONSULTADAS}

Currículo Nacional do Ensino Básico - Competências Essenciais 2001, Ministério da Educação - Departamento de Educação Básica, Lisboa.

Gomes, M. C. (coord.) 2006, Referencial de Competências-Chave para a Educação e Formação de Adultos - Nivel Secundário, Ministério da Educação e Direcção-Geral de Formaçáo Vocacional, Lisboa.

Rodrigues, S. 2009, Guia de Operacionalização de cursos de educação e formação de adultos, ANQ - Agência Nacional para a Qualificação, Lisboa.

\section{REFERÊNCIAS BIBLIOGRÁFICAS}

Alves, L. A. 2006, 'A História local como estratégia para o ensino da História' in Estudos em homenagem ao Professor Doutor José Marques, Faculdade de Letras da Universidade do Porto - Departamento de História e Departamento de Ciências e Técnicas do Património, vol. 3, Porto, p. 65-72.

Alves, L. A. 2009, 'Ensino Técnico - uma necessidade ou uma "falácia"? Notas para a compreensão da filosofia do ensino técnico em Portugal' in Alves, L. A., Sousa, P., Morais, T., Araújo, F., Ensino Técnico (17561973), Secretaria-Geral do Ministério da Educação, Lisboa, p. 17-55.

Barreira, A., Moreira, M. 2004, Pedagogia das Competências - da teoria à prática, Ediçóes Asa, Porto.

Barroso, J. 2001, 'O Século da Escola: Do Mito da Reforma à Reforma de um Mito' in O Século da Escola. Entre e Utopia e a Burocracia, Ediçóes Asa, Porto, p. 63-90.

Claudino, S. 2005, 'A Situação Actual da Geografia e dos Geógrafos Portugueses: uma Perspectiva' in X Colóquio Ibérico de Geografia, Évora.

Crato, N. 2006, 'A teoria das competências contra os conteúdos' in $O$ 'Eduquês' em discurso directo - Uma Crítica da Pedagogia Romântica e Construtivista, Gradiva, Lisboa, p. 75-79.

Estrela, M. E., Esteves, M., Rodrigues, A. 2002, Síntese da Investigação sobre Formação Inicial de Professores em Portugal (1990-2000), Porto Editora \& Ministério da Educação/Instituto Nacional de Acreditação da Formação de Professores, Porto.

Gil, A. 2009, 'O geógrafo: da universidade ao mercado de trabalho' in Cadernos - Curso de Doutoramento em Geografia, Faculdade de Letras da Universidade do Porto, Porto, p. 167-188.

Gouveia, J. 2007, 'Competências: moda ou inevitabilidade' in Saber (e) Educar, 12, p. 31-58.

Lavrador, A., Reis, J., Carneiro, L. 2009 'Experiências Educativas no Contexto dos Cursos de Educação e Formação de Adultos' in Actas do IV Congresso Ibérico de Didáctica da Geografia - A Inteligência Geográfica na Educação do Século XXI - cdrom, APG, AGE \& IGOT, Lisboa.

Legendre, M.-F. 2008, 'La notion de compétence au coeur des réformes curriculaires: effet de mode ou moteur de changements en profondeur?' in Audigier, F., Tutiaux-Guillon, N. (dir) 2008, Compétences et contenus Les curriculums en questions, De Boeck, Bruxelles, p. 27-50.

Ollagnier, E. 2004, 'As armadilhas da competência na formação de adultos' in Dolz, J., Ollagnier, E., O enigma da competência em Educação, Artmed, Porto Alegre, p. 189-208.

Pacheco, J. A. 2003, 'Competências curriculares: as práticas ocultas nos discursos das reformas' in Revista de Estudos Curriculares, n. ${ }^{\circ}$ 1, p. 59-77. 
Perrenoud, Ph. 1999, Construir as Competências desde a Escola, Artmed Editora, Porto Alegre.

Perrenoud, Ph. 2005, Escola e Cidadania - O papel da escola na formaçáo para a democracia, Artmed, Porto Alegre.

Perrenoud, Ph. 2001, Porquê construir competências a partir da escola? - Desenvolvimento da autonomia e luta contra as desigualdades, Ediçóes Asa, Porto.

Pinto, J. M. 2007, 'A escola e a sala de aula na "sociedade cognitiva»' in Indagação Científica, Aprendizagens Escolares, Reflexividade Social, Ediçóes Afrontamento, Porto, p. 115-187.

Quaresma, C. 2009, Biografias em Metamorfose? - A Cidadania como Competência-Chave Aprendida ao Longo da Vida, [Dissertação de Mestrado em Ciências da Educação, Especialização em Educação, Género e Cidadanias], Faculdade de Psicologia e Ciências da Educação da Universidade do Porto, Porto.

Roldão, M. C. 2004, Gestão do Currículo e Avaliação de Competências, Editorial Presença, Lisboa.

Sá-Chaves, I. 2005, Os "portefólios" reflexivos (também) trazem gente dentro - reflexóes em torno do seu uso na humanização dos processos educativos, Porto Editora, Porto. 